\title{
Factors associated with (non-)participation of cancer survivors with job loss in a supportive return to work program
}

\author{
Martine P. van Egmond ${ }^{1,2} \cdot$ Johannes R. Anema ${ }^{1,2} \cdot$ Amika Singh $^{1} \cdot$ Allard J. van der Beek $^{1,2}$. \\ Saskia F. A. Duijts ${ }^{1,3}$
}

Received: 9 December 2015 / Accepted: 9 February 2016 / Published online: 2 March 2016

(C) The Author(s) 2016. This article is published with open access at Springerlink.com

\begin{abstract}
Purpose To evaluate and implement supportive programs, it is important to understand which cancer survivors (CSs) are participating in these programs and which motives exist for declining participation. Recently, a supportive return-to-work (RTW) program was offered to CSs with job loss. The purpose of this study was to identify factors and motives associated with (non-)participation of CSs with job loss in the RTW program.

Methods In this cross-sectional study $(N=286)$, information on socio-demographic, health-related, psychosocial, and work-related characteristics of CSs in the program was collected. Similar data were collected from those who declined participation. Multivariable logistic regression analyses were conducted $(p<0.05)$ to identify factors associated with (non-)participation. Motives for declining participation were identified using descriptive analysis.

Results Being married (odds ratio (OR) 0.23; $95 \%$ confidence interval (CI) $0.08-0.69$ ) or living together (OR $0.25 ; 95 \%$ CI $0.07-0.96)$ decreased the likelihood of participation in the RTW program. Having a temporary
\end{abstract}

This study was supported by the Dutch Social Security Agency

Johannes R. Anema

h.anema@vumc.nl

1 Department of Public and Occupational Health, EMGO+ Institute for Health and Care Research, VU University Medical Center, Van der Boechorststraat 7, C581, 1081, BT Amsterdam, The Netherlands

2 Research Center for Insurance Medicine, AMC-UMCG-UWV-VUmc, Amsterdam, The Netherlands

3 Department of Psychosocial Research and Epidemiology, The Netherlands Cancer Institute, Amsterdam, The Netherlands employment contract prior to unemployment (OR 2.60; $95 \%$ CI 1.20-5.63), a clear intention to RTW (OR 2.65; $95 \%$ CI 1.20-5.82), and higher scores on a readiness to RTW instrument, i.e., contemplation scale (OR $2.00 ; 95 \%$ CI 1.65-2.40) and prepared for action-selfevaluative scale (OR 1.27; $95 \%$ CI 1.04-1.54), increased the likelihood of participation. Physical (50\%) and mental problems (36\%) were leading motives for declining participation.

Conclusions The results from this study help to distinguish CSs that may not need RTW support, from those who are most in need of RTW support. Practitioners and researchers should tailor RTW support to CSs' socio-demographic, health-related, and work-related characteristics.

Keywords Cancer survivors · Unemployment · Return to work $\cdot$ Intervention $\cdot$ Participation

$\begin{array}{ll}\text { Abbreviations } \\ \text { CS(s) } & \text { Cancer Survivor(s) } \\ \text { RTW } & \text { Return To Work } \\ \text { RTC } & \text { Randomized Controlled Trial } \\ \text { SSA } & \text { Social Security Agency }\end{array}$

\section{Introduction}

Annually, 1.7 million persons at working age (15-65 years) are diagnosed with cancer in the European Union, of which 40,000 in the Netherlands [1, 2]. For most cancer survivors (CSs), motivation for work participation remains during and/ or after treatment $[3,4]$. Eventually, $64 \%$ of CSs return to work (RTW) [5]. However, a considerable part of CSs does not RTW. That is, CSs' work ability may be affected by long- 
term or permanent health problems, such as fatigue or cognitive impairments [6-8]. Further, other cancer-related, psychosocial, and work-related factors, e.g., an unfavorable cancer prognosis and lack of support from employer and colleagues, may reduce the chance of RTW [9].

RTW can be especially challenging for CSs who become unemployed [10]. Between 26 and $53 \%$ of CSs lose their job or quit working during or after treatment [5]. In Western countries, these percentages have been increasing [11], which is partly explained by the increasing popularity of temporary employment contracts among employers [12] and the rising retirement age [13]. In the Netherlands, CSs who become unemployed during sick leave can apply for financial support, i.e., sickness benefits, at the Social Security Agency (SSA). These benefits partly cover the former salary, with a maximum of 2 years. During sick leave, RTW options are limited for CSs with job loss, as they lack support from an employer and colleagues, as well as opportunities for gradual RTW [14, 15]. In contrast, CSs with a fixed employment contract benefit from employment security during the first 2 years of sick leave, i.e., a certain level of financial stability, RTW support, and options for workplace accommodations. Given this contrast, the RTW process of CSs with job loss may be more complicated than the RTW process of employed CSs [10]. To support Dutch CSs with job loss, a supportive RTW program was recently developed and offered in an experimental setting [16].

When offering supportive programs to CSs, it is important to consider the role of (non-)participation, as generally only a selection of the invited CSs participates in these programs [17]. For example, with regard to supportive RTW interventions for CSs in the Netherlands, in a previous hospital-based supportive RTW program for female CSs, $74 \%$ signed up to participate [18]. Further, in a study evaluating the effects of a high-intensity physical rehabilitation program on RTW for CSs who had received chemotherapy, $85 \%$ was interested to partake [19]. So far, factors and motives associated with (non-)participation of CSs have mainly been studied within the context of clinical trials, i.e., trials in which new cancer treatments are evaluated $[20,21]$. However, the circumstances for participation in clinical studies differ from those for participation in studies offering supportive programs. That is, clinical studies take place in a different setting, i.e., laboratory or hospital, and may appeal to a different kind of motivation for participation, e.g., receiving experimental treatment or financial incentives.

Evaluating (non-)participation in supportive programs for CSs may provide information to optimize recruitment procedures and facilitate proper interpretation of the effects of these programs. Therefore, the aim of the current study is to identify factors and motives associated with (non-)participation of CSs with job loss in a supportive RTW program.

\section{Methods}

\section{Design}

In this cross-sectional study, we used data from CSs with job loss, invited to participate in a supportive RTW program within a randomized controlled trial (RCT). Questionnaire data of CSs interested to participate in the RTW program were collected, as well as data from CSs who declined participation, who were willing to complete a one-time questionnaire. The SSA provided additional data from all invited CSs, for comparison between participants and non-participants. The study procedures of the RCT have been published previously [16].

\section{Study population}

CSs with job loss were eligible for participation in the RTW program if they were registered at the SSA as recipients of sickness or disability benefits for a period of 12-36 months after first day of sick leave. Furthermore, eligible CSs were 18 to 60 years old, had completed intensive cancer treatment at least 6 weeks prior to the start of the RTW program, and were free of comorbidities that interfered with participation (based on report by CSs' general physician). Also, their health had to be sufficient to participate (based on self-report). CSs were excluded from participation in case of the following: a lack of knowledge of the Dutch language, a conflict with the SSA regarding a (previous) benefits claim, and (registration for) participation in a concurrent scientific study and/or supportive program.

\section{Study procedure}

CSs with job loss were recruited through the SSA registries. Invitations were sent by mail to potentially eligible CSs, throughout the Netherlands, from April 2013 to January 2015. The invitation included an information flyer, a screening questionnaire, an informed consent form, and a postcard. CSs who were interested in participation in the RTW program could respond by returning the screening questionnaire and informed consent form. The researchers checked the inclusion and exclusion criteria during a telephone conversation, after which eligible CSs received a baseline questionnaire and a second informed consent form. After returning the baseline questionnaire and informed consent form, CSs were included in the study. After returning the baseline questionnaire and informed consent form, CSs were included in the study. At this point, an information letter was sent to CSs' general physician, to inform them about the study and ask them to notify the researchers of any comorbidities that could interfere with participation in the program. If so, the researchers would deliberate with the physician whether or not the program was appropriate. CSs could also decline by returning a postcard, on which they could indicate personal or predetermined 
motives for declining, e.g., "I am experiencing physical health problems" or "I have already found a new job." Further, CSs could disclose on the postcard whether they were interested in completing a one-time questionnaire. CSs who were interested received this questionnaire, including an informed consent form, shortly after their decline. The one-time questionnaire for non-participants in the supportive program was identical to the baseline questionnaire for participants.

\section{The supportive RTW program}

The supportive RTW program was developed as a tailored program, i.e., the more support CSs needed, the further they proceeded in the program. Participating CSs were supported by reintegration professionals to develop a consensus-based RTW plan, which included coaching on various themes, e.g., RTW planning or coping with cancer, and actual job placement. A detailed description of the supportive RTW program has been published previously [16].

\section{Measurements}

The dependent variable of the current study is participation (yes; no) in the supportive RTW program. Independent variables potentially associated with the dependent variable were as follows:

- Socio-demographics: age (in years), gender (male; female), level of education (no education/primary school/ lower vocational education; secondary school; vocational education/upper secondary school; upper vocational education/university), principal wage earner (yes; no), marital status (single; married; living together with partner, children and/or others; divorced/widowed), having children (yes; no), and ethnicity (Dutch; non-Dutch).

- Health-related and psychosocial variables: tumor type, treatment modalities (no treatment; surgery; radiotherapy; chemotherapy; hormone therapy; immunotherapy; other treatment (yes; no)); being declared free of disease by physician/specialist (yes; no), comorbidity (yes; no), levels of depressive symptoms (assessed using Centre for Epidemiological Studies Depression Scale (CES-D), of which the scores were dichotomized, using the predetermined cutoff point of $>16$ points to indicate risk of clinical depression [22-24]), fatigue (assessed using the Functional Assessment of Chronic Illness Therapy Fatigue Scale (FACIT-Fatigue)) [25], coping preferences (assessed using the Utrecht Coping List (UCL)) [26], and general health and quality of life (levels of functioning), i.e., physical emotional, social, cognitive, and role functioning; sleeping problems; and financial problems due to illness (assessed using the European Organization for
Research and Treatment of Cancer Quality of Life Questionnaire (EORTC QLQ C-30)) [27].

- Work-related variables: characteristics of previous job, i.e., type of sector (blue collar; white collar; civil servant; health care worker), working hours (hours/week), shift work (yes; no), managerial tasks (yes; no), type of job demands (psychological; physical; both), and type of employment contract (fixed; temporary; temporary agency work; other). Further, total number of years working, level of perceived work ability compared to lifetime best (assessed using the Work Ability Index (WAI)) [28], participation in society, e.g., participation in voluntary work, studies, and daily activities (assessed using the Utrecht Scale for Evaluation of Revalidation and Participation (USER-P), containing three scales: frequency of participation, restrictions in participation, and satisfaction with participation [29]), and readiness to RTW (assessed using the Readiness to RTW instrument (RRTW)) [30], related to the five stages of change that are described in the transtheoretical model by Prochaska and DiClemente [31], and intention to RTW (uncertain or no intention to RTW; clear intention to RTW) (assessed using the Attitudes-Social influence-self-Efficacy questionnaire (ASE)) [32].

\section{Statistical analyses}

Descriptive analyses, $t$ tests, and chi-square tests were used to describe differences in self-reported socio-demographic, health-related and psychosocial, and work-related characteristics of participants (interested in the RTW program) and nonparticipants who completed the one-time questionnaire.

Further, the SSA provided data regarding age, gender, and cancer diagnosis for all invited CSs. $t$ tests and chi-square tests were used to study potential differences in characteristics among CSs in four groups, i.e., (1) participants (CSs interested to participate in the RTW program), (2) non-participants who completed the one-time questionnaire, (3) non-participants who only returned the postcard, and (4) CSs who did not respond to the invitation at all.

To construct a multivariable hierarchical model for participants and non-participants (one-time questionnaire), first, univariate analyses between the independent variables and the dependent variable, i.e., (non-)participation in the RTW program, were conducted. All variables with $p$ value $<0.2$ were considered for the model and tested for multicollinearity before continuing analysis. Variables with correlation coefficients of $<-0.8$ or $>0.8$ were removed from the analyses [33].

Using multiple logistic regression analysis, variables were entered into one of three cluster models, i.e., socio-demographic, health-related and psychosocial, or work-related model. All variables with a $p$ value $<0.1$ in the cluster models were considered eligible for the multivariable model. The final 
multivariable model had a cutoff point of $p$ value $<0.05$. Goodness of fit of the model was described using Nagelkerke $R$-squared.

Using descriptive statistics, motives for declining to participate in the supportive RTW program were analyzed. SPSS version 20.0 was applied to conduct the analyses [34].

\section{Results}

\section{Characteristics of (non-)participants}

Of the 2757 invited CSs with job loss, 786 (29\%) were interested to participate in the supportive RTW program, of whom 171 met the inclusion criteria. Six hundred forty-seven CSs $(23 \%)$ declined participation by returning the postcard. Of these, 115 (18\%) completed the one-time questionnaire. One thousand two hundred eighty-four CSs (47 \%) did not respond to the invitation at all (Fig. 1).

The mean age of participants in the RTW program was 48.4 years (SD 8.6), $69 \%$ was female, $57 \%$ was the principal wage earner, and $48 \%$ was married. In the group of nonparticipants (one-time questionnaire), the mean age was 50.9 (SD 8.9), $66 \%$ was female, $45 \%$ was the principal wage earner, and $65 \%$ was married. In both groups, over $90 \%$ had the Dutch nationality, and the majority (39-40\%) had suffered from breast cancer (Table 1).

Using the SSA data, we found no significant differences in gender between participating CSs and any of the nonparticipating CSs. Participating CSs were significantly younger than non-participants who completed the one-time questionnaire (mean difference (MD) 2.6 years; $p=0.015$ ) and non-participants who only returned the postcard (MD 1.9 years; $p=0.012$ ). CSs who did not respond to the invitation at all were significantly younger compared to the other CSs, i.e., participants (MD 2.6 years; $p<0.001$ ), nonparticipants (one-time questionnaire) (MD 4.8 years; $p<0.001$ ), and non-participants (postcard only) (MD 4.6 years; $p<0.001$ ). Also, the proportion of breast CSs was significantly lower in CSs that did not respond to the invitation at all than participants $(p<0.001)$, non-participants (one-time questionnaire) $(p=0.014)$, and non-participants (postcard only) $(p=0.015)$. The proportions of other cancer diagnoses in the groups were too small for analysis.

\section{Factors associated with (non-)participation in the RTW program}

Questionnaire data from participants $(N=171)$ and nonparticipants (one-time questionnaire) $(N=115)$ were merged into a sample of 286 . The univariate analysis identified 31 factors associated with (non-)participation in the RTW program (Table 1). These factors were considered for multiple

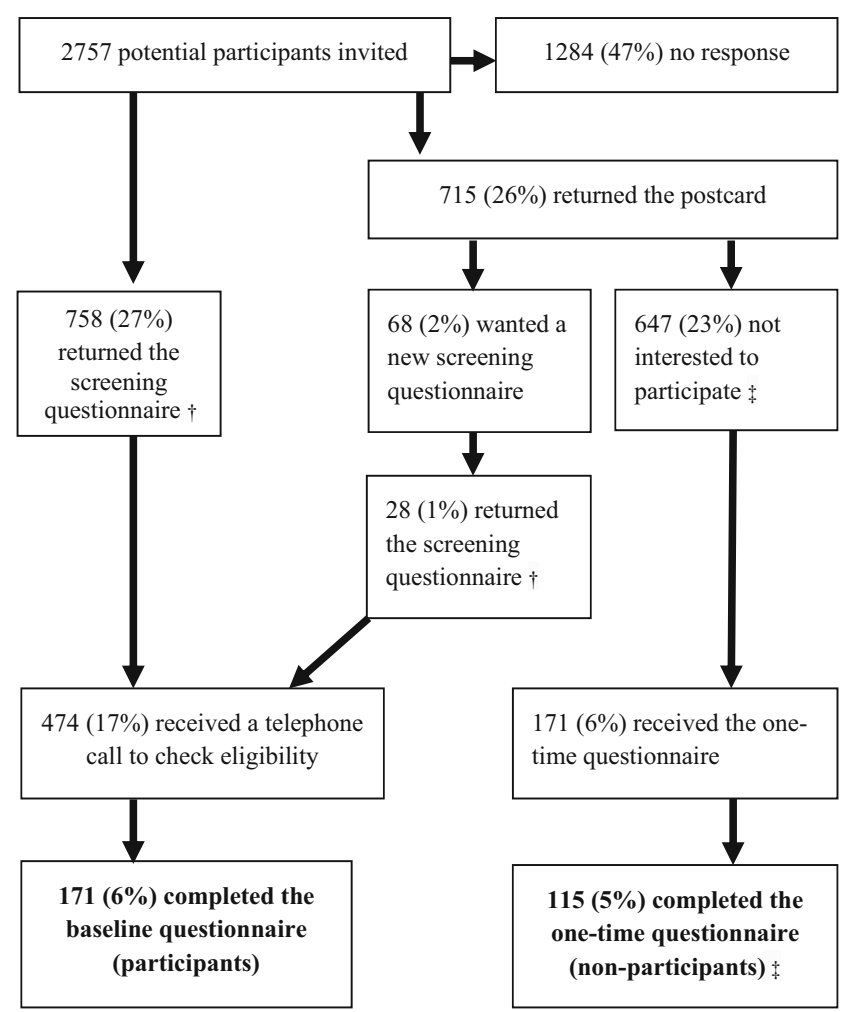

Fig. 1 Recruitment flow diagram. Percentages were calculated from the number of potential participants invited $(N=2757)$. Combined percentages mentioned in the text may differ by $1 \%$ because of rounding differences; $\$ 786 \mathrm{CSs}$ were interested to participate in the program, calculated as the sum of 758 and 28 returned screening questionnaires; $\$ 532 \mathrm{CSs}$ only returned the postcard (calculated as the difference between 647 CSs who returned the postcard and the $115 \mathrm{CSs}$ who returned the postcard and the one-time questionnaire)

regression analysis within their cluster, i.e., socio-demographic, health-related and psychosocial, or work-related cluster. The factors "diagnosis: skin cancer/melanoma" and "treatment modalities: no treatment" were removed due to the low number of cases.

In the cluster models, 11 factors were associated with a lower chance of participation in the RTW program, i.e., higher age, marital status (married or living with someone), having had lung cancer and/or surgery, having no/an unclear intention to RTW, having had a fixed employment contract, having had both physically and psychologically high demands in a previous job, and lower scores on various scales, i.e., physical functioning, coping preference - active tackling, readiness to RTW - contemplation phase, and readiness to RTW - prepared for action-self-evaluative phase. These factors were entered into a multivariable model (Table 2).

The multivariable model showed that CSs with job loss who were married (odds ratio (OR) $0.23 ; 95 \%$ confidence interval (CI) 0.08-0.69) or living together (OR 0.25; $95 \%$ CI 0.07-0.96) were significantly less likely to participate than CSs living alone. CSs who had a temporary employment contract prior to job loss were significantly more likely to 
Table 1 Characteristics of (non-)participating CSs with job loss in a supportive RTW program

\begin{tabular}{|c|c|c|c|c|c|}
\hline Group & Variable & Categories & $\begin{array}{l}\text { Participants } \\
(N=171) \\
\text { Mean (SD) }\end{array}$ & $\begin{array}{l}\text { Non-participants } \\
(N=115) \\
\text { Mean (SD) }\end{array}$ & $\begin{array}{l}P \\
\text { value }^{\mathrm{a}}\end{array}$ \\
\hline \multirow[t]{18}{*}{ Socio-demographics } & \multirow[t]{2}{*}{ Age (years) } & & $48.4(8.6)$ & $50.9(8.9)$ & 0.015 \\
\hline & & & $N(\%)^{\mathrm{b}}$ & $N(\%)^{\mathrm{b}}$ & \\
\hline & \multirow[t]{2}{*}{ Gender } & Male & $53(31)$ & $39(34)$ & 0.569 \\
\hline & & Female & $118(69)$ & $75(66)$ & \\
\hline & \multirow[t]{4}{*}{ Level of education } & None/primary/lower & $30(18)$ & $31(27)$ & 0.106 \\
\hline & & vocational education & $28(16)$ & $24(21)$ & \\
\hline & & Secondary school & $60(35)$ & $31(27)$ & \\
\hline & & $\begin{array}{l}\text { Vocational education/upper } \\
\text { secondary school } \\
\text { Upper vocational education/ } \\
\text { university }\end{array}$ & $53(31)$ & $28(25)$ & \\
\hline & \multirow[t]{2}{*}{ Principal wage earner } & No & $74(44)$ & $61(55)$ & 0.061 \\
\hline & & Yes & $96(57)$ & $50(45)$ & \\
\hline & \multirow[t]{4}{*}{ Marital status } & Living alone & $36(21)$ & $13(11)$ & 0.031 \\
\hline & & Married & $81(48)$ & $74(65)$ & \\
\hline & & Living together & $28(17)$ & $16(14)$ & \\
\hline & & Divorced/widowed & $24(14)$ & $11(10)$ & \\
\hline & \multirow[t]{2}{*}{ Having children } & No & $59(35)$ & $29(25)$ & 0.095 \\
\hline & & Yes & $112(66)$ & $86(75)$ & \\
\hline & \multirow[t]{2}{*}{ Ethnicity } & Dutch & $163(95)$ & $105(91)$ & 0.170 \\
\hline & & Non-Dutch & $8(5)$ & $10(9)$ & \\
\hline \multirow{29}{*}{$\begin{array}{l}\text { Health-related and psychosocial } \\
\text { factors }\end{array}$} & \multirow[t]{12}{*}{ Tumor type } & Breast & $68(40)$ & $45(39)$ & 0.914 \\
\hline & & Lung & $3(2)$ & $11(10)$ & 0.003 \\
\hline & & Gynecological & $7(4)$ & $2(2)$ & 0.263 \\
\hline & & Colon & $13(8)$ & $9(8)$ & 0.944 \\
\hline & & Gastro-intestinal & $10(6)$ & $5(4)$ & 0.577 \\
\hline & & Head and neck & $8(5)$ & $4(4)$ & 0.620 \\
\hline & & Skin/melanoma & $0(0)$ & $4(4)$ & 0.014 \\
\hline & & Prostate & $3(2)$ & $5(4)$ & 0.192 \\
\hline & & Hematological & $23(14)$ & $7(6)$ & 0.046 \\
\hline & & Brain & $8(5)$ & $7(6)$ & 0.600 \\
\hline & & Other type of cancer & $24(14)$ & $9(8)$ & 0.107 \\
\hline & & Cancer recurrence & $4(2)$ & $7(6)$ & 0.106 \\
\hline & \multirow[t]{7}{*}{ Treatment modalities } & No treatment & $2(1)$ & $0(0)$ & 0.247 \\
\hline & & Surgery & $124(73)$ & $93(82)$ & 0.079 \\
\hline & & Radiotherapy & $84(49)$ & $51(45)$ & 0.468 \\
\hline & & Chemotherapy & $109(64)$ & $70(61)$ & 0.689 \\
\hline & & Hormone therapy & $47(28)$ & $25(22)$ & 0.290 \\
\hline & & Immunotherapy & $13(8)$ & $7(6)$ & 0.636 \\
\hline & & Other type of treatment & $13(8)$ & $5(4)$ & 0.274 \\
\hline & \multirow[t]{2}{*}{ Declared free of disease } & No & $56(33)$ & $49(44)$ & 0.063 \\
\hline & & Yes & $113(67)$ & $62(56)$ & \\
\hline & \multirow[t]{2}{*}{ Comorbidity } & No & $87(51)$ & $46(40)$ & 0.081 \\
\hline & & Yes & $84(49)$ & $68(60)$ & \\
\hline & \multirow[t]{3}{*}{ Depression } & No depressive symptoms & $101(59)$ & $68(60)$ & 0.968 \\
\hline & & At risk of depression & $69(41)$ & $46(40)$ & \\
\hline & & & Mean (SD) & Mean (SD) & \\
\hline & Fatigue & $(0-52)$ & $33.0(9.8)$ & $30.0(11.2)$ & 0.018 \\
\hline & \multirow[t]{2}{*}{ Coping } & Active tackling (7-28) & $18.6(3.9)$ & $17.0(3.6)$ & 0.001 \\
\hline & & Seeking social support (6-24) & $13.3(4.0)$ & $13.2(3.4)$ & 0.705 \\
\hline
\end{tabular}


Table 1 (continued)

\begin{tabular}{|c|c|c|c|c|c|}
\hline Group & Variable & Categories & $\begin{array}{l}\text { Participants } \\
(N=171) \\
\text { Mean (SD) }\end{array}$ & $\begin{array}{l}\text { Non-participants } \\
(N=115) \\
\text { Mean (SD) }\end{array}$ & $\begin{array}{l}P \\
\text { value }^{\mathrm{a}}\end{array}$ \\
\hline \multirow{42}{*}{ Work-related factors } & \multirow{14}{*}{$\begin{array}{l}\text { Health-related quality of } \\
\text { life (levels } \\
\text { of functioning) }\end{array}$} & Palliative reacting (8-32) & $18.7(3.4)$ & $17.9(3.3)$ & 0.050 \\
\hline & & Avoiding (8-32) & $16.4(3.5)$ & $16.6(3.2)$ & 0.631 \\
\hline & & Passive reacting (7-28) & $12.7(3.3)$ & $12.3(3.3)$ & 0.320 \\
\hline & & Reassuring thoughts $(5-20)$ & $12.5(2.6)$ & $12.4(2.4)$ & 0.779 \\
\hline & & Expression of emotions (3-12) & $6.0(1.7)$ & $5.8(1.7)$ & 0.290 \\
\hline & & Quality of life(0-100) & $63.7(17.3)$ & $53.5(21.1)$ & 0.000 \\
\hline & & Physical functioning $(0-100)$ & $78.8(14.8)$ & $68.4(20.7)$ & 0.000 \\
\hline & & Emotional functioning $(0-100)$ & $64.1(25.0)$ & $64.2(26.3)$ & 0.947 \\
\hline & & Social functioning $(0-100)$ & $69.0(26.0)$ & $60.2(26.6)$ & 0.006 \\
\hline & & Cognitive functioning $(0-100)$ & $66.5(26.9)$ & $64.7(25.5)$ & 0.590 \\
\hline & & Role functioning (0-100) & $63.1(26.4)$ & $54.5(28.7)$ & 0.010 \\
\hline & & Sleeping problems $(0-100)$ & $37.8(33.8)$ & $44.1(33.4)$ & 0.126 \\
\hline & & Financial problems $(0-100)$ & $40.6(35.6)$ & $37.8(32.1)$ & 0.495 \\
\hline & & & $N(\%)^{\mathrm{b}}$ & $N(\%)^{\mathrm{b}}$ & \\
\hline & \multirow{4}{*}{$\begin{array}{l}\text { Type of sector previous } \\
\text { job }\end{array}$} & Blue collar & $12(7)$ & $11(10)$ & 0.616 \\
\hline & & White collar & $58(35)$ & $43(39)$ & \\
\hline & & Civil servant & $56(33)$ & $35(32)$ & \\
\hline & & Health care worker & $42(25)$ & $22(20)$ & \\
\hline & \multirow{4}{*}{$\begin{array}{l}\text { Type of previous } \\
\text { employment contract }\end{array}$} & Fixed employment & $49(23)$ & $55(50)$ & 0.001 \\
\hline & & Temporary employment & $95(57)$ & $41(37)$ & \\
\hline & & Temporary agency work & $21(13)$ & $10(9)$ & \\
\hline & & Other type of contract & $2(1)$ & $5(5)$ & \\
\hline & \multirow[t]{2}{*}{ Shift work previous job } & No & $51(30)$ & $36(32)$ & 0.727 \\
\hline & & Yes & $118(70)$ & $77(68)$ & \\
\hline & \multirow{2}{*}{$\begin{array}{l}\text { Managerial tasks } \\
\text { previous job }\end{array}$} & No & $134(79)$ & $90(80)$ & 0.942 \\
\hline & & Yes & $35(21)$ & $23(20)$ & \\
\hline & \multirow[t]{3}{*}{ Previous job demands } & Psychological and physical & $51(30)$ & $46(42)$ & 0.030 \\
\hline & & Mainly psychological & $73(44)$ & $31(28)$ & \\
\hline & & Mainly physical & $44(26)$ & $33(30)$ & \\
\hline & \multirow[t]{3}{*}{ Intention to RTW } & $\begin{array}{l}\text { Uncertain or no intention to } \\
\text { RTW }\end{array}$ & $49(29)$ & $72(64)$ & 0.000 \\
\hline & & Clear intention to RTW & $122(71)$ & $40(36)$ & \\
\hline & & & Mean (SD) & Mean (SD) & \\
\hline & $\begin{array}{l}\text { Total number of years } \\
\text { working }\end{array}$ & & $24.1(10.1)$ & $26.7(10.5)$ & 0.038 \\
\hline & $\begin{array}{l}\text { Working hours a week } \\
\text { previous job }\end{array}$ & & $28.9(11.5)$ & $27.3(11.9)$ & 0.246 \\
\hline & Work ability & $(0-10)$ & $4.6(2.0)$ & $3.3(2.5)$ & 0.000 \\
\hline & \multirow[t]{3}{*}{$\begin{array}{l}\text { Participation in } \\
\text { daily activities }\end{array}$} & $\begin{array}{l}\text { Frequency of participation } \\
\quad(0-100)\end{array}$ & $32.1(8.2)$ & $28.9(10.9)$ & 0.006 \\
\hline & & $\begin{array}{l}\text { Restrictions in participation } \\
\quad(0-100)\end{array}$ & $81.8(13.8)$ & $75.4(18.5)$ & 0.001 \\
\hline & & $\begin{array}{l}\text { Satisfaction with participation } \\
\quad(0-100)\end{array}$ & $63.5(15.2)$ & $62.3(16.1)$ & 0.542 \\
\hline & \multirow{4}{*}{$\begin{array}{l}\text { Readiness to } \\
\text { RTW stages }\end{array}$} & Precontemplation $(1-15)$ & $4.9(2.1)$ & $6.9(3.4)$ & 0.000 \\
\hline & & Contemplation (1-15) & $12.1(1.9)$ & $8.7(2.9)$ & 0.000 \\
\hline & & $\begin{array}{l}\text { Prepared for action-self } \\
\text { evaluative }(1-10)\end{array}$ & $6.8(1.8)$ & $5.3(2.5)$ & 0.000 \\
\hline & & $\begin{array}{l}\text { Prepared for action-behavioral } \\
\quad(1-15)\end{array}$ & $9.8(2.2)$ & $9.4(3.2)$ & 0.302 \\
\hline
\end{tabular}

${ }^{\text {a }} P$ values are the result of $t$ tests and chi-square tests for univariate associations between participants and non-participants

${ }^{\mathrm{b}} N$ and calculated percentages may approach or exceed the total $N$ and $100 \%$ because of missing values or rounding differences 
Table 2 Multivariable model of factors associated with (non-)participation of cancer survivors with job loss in the supportive RTW program

\begin{tabular}{|c|c|c|c|c|}
\hline Group & Factor & Categories & Odds ratio $(95 \% \mathrm{CI})$ & $P$ value \\
\hline \multirow[t]{4}{*}{ Socio-demographics } & \multirow[t]{4}{*}{ Marital status } & Living alone & Ref. & \\
\hline & & Married & $0.23(0.08-0.69)$ & 0.009 \\
\hline & & Living together & $0.25(0.07-0.96)$ & 0.044 \\
\hline & & Divorced/widowed & $0.82(0.18-3.67)$ & 0.790 \\
\hline \multirow[t]{9}{*}{ Work-related factors } & \multirow{5}{*}{$\begin{array}{l}\text { Type of employment contract prior } \\
\text { to loss of employment }\end{array}$} & Fixed employment contract & Ref. & \\
\hline & & Temporary employment & $2.60(1.20-5.63)$ & 0.016 \\
\hline & & contract & $2.41(0.71-8.17)$ & 0.157 \\
\hline & & Temporary agency work contract & $0.24(0.25-2.38)$ & 0.224 \\
\hline & & Other type of contract & & \\
\hline & \multirow[t]{2}{*}{ Intention to RTW } & Uncertain or no intention to RTW; & Ref. & \\
\hline & & Clear intention to RTW & $2.65(1.20-5.82)$ & 0.015 \\
\hline & Readiness to RTW stage 2: contemplation ${ }^{\mathrm{a}}$ & & $2.00(1.65-2.40)$ & 0.000 \\
\hline & $\begin{array}{l}\text { Readiness to RTW stage 3: prepared for } \\
\text { action-self evaluative }^{\mathrm{a}}\end{array}$ & & $1.27(1.04-1.54)$ & 0.017 \\
\hline
\end{tabular}

The model is based on $261 \mathrm{CSs}$, because of missing values

${ }^{a}$ Higher score in this stage is associated with a higher chance of participation in the RTW program

participate than CSs who had had a fixed employment contract prior to loss of employment (OR 2.60; $95 \%$ CI 1.20 5.63). Also, CSs with a clear intention to RTW were significantly more likely to participate than CSs with no or an unclear intention to RTW (OR 2.65; $95 \%$ CI 1.20-5.82). Finally, higher scores on the contemplation scale (OR 2.00; $95 \%$ CI 1.65-2.40) and the prepared for action-self-evaluative scale (OR 1.27; $95 \%$ CI 1.04-1.54) of the Readiness to RTW scale, meaning that a person is contemplating RTW or starting to prepare for RTW, were significantly associated with participation in the program. The Nagelkerke $R$-squared demonstrated that the model is of reasonable quality ( $p$ value $0.580)$.

\section{Motives for declining participation in the supportive RTW program}

The most frequently reported motives for declining participation were physical motives (50.4 \%), e.g., experiencing physical limitations or still undergoing cancer treatment, and mental motives (36.3\%), e.g., experiencing anxiety or depression (Table 3). On over $40 \%$ of the postcards, more than one motive for declining participation was listed.

\section{Discussion}

\section{Main findings}

The results of this study demonstrate that CSs who were unmarried and/or lived alone and who had a temporary employment contract prior to job loss, a clear intention to RTW, and higher scores on the contemplation scale and the prepared for action-self-evaluative scale of the Readiness to RTW scale were more likely to participate. Physical and mental problems were the main reasons for declining participation.

\section{Interpretation of the findings}

Non-participants (one-time questionnaire and postcard only) and participants in this study were significantly older than CSs who did not respond to the invitation at all. Previous studies have that shown that younger CSs are more likely to RTW $[16,35-37]$. In the general population, younger persons are less challenged in finding new employment and may need less support, compared to older persons [38]. This might be true for CSs as well. That is, facing fewer RTW challenges than older CSs could explain why younger CSs were less interested to participate in a supportive RTW program. This could imply that supportive RTW interventions should be directed more toward the needs of older sick-listed workers [39].

Further, groups of non-participants (one-time questionnaire and postcard only) and participants included significantly higher proportions of breast CSs, compared to nonparticipants who did not respond to the invitation at all. This seems in line with previous studies, which also found that breast CSs participate frequently in supportive interventions $[40,41]$. The relatively high number of breast CSs in our supportive RTW program may be partly explained by the generally favorable prognosis of breast cancer and relatively low impact on work ability, compared to other types of cancer in the occupational age [7].

CSs with job loss who were married or living together were less likely to participate in the RTW program than CSs who 
Table 3 Motives for declining participation in the supportive RTW program

\begin{tabular}{|c|c|c|c|c|}
\hline Motives & $\begin{array}{l}\text { Non-participants } \\
N(\% \text { of } 647)\end{array}$ & $\begin{array}{l}\text { Non-participants } \\
\text { postcard } N(\% \text { of } 532)^{\mathrm{a}}\end{array}$ & $\begin{array}{l}\text { Non-participants } \\
\text { questionnaire } N(\% \text { of } 115)^{\mathrm{b}}\end{array}$ & $P$ value $^{\mathrm{c}}$ \\
\hline Physical reasons & $326(50.4 \%)$ & $282(53.0)$ & $44(38.3)$ & 0.004 \\
\hline Mental reasons & $235(36.3 \%)$ & $210(39.5)$ & $25(21.7)$ & 0.000 \\
\hline Negative associations with RTW & $87(13.4 \%)$ & $78(14.7)$ & $9(7.8)$ & 0.051 \\
\hline Not willing to participate in a RCT & $34(5.3 \%)$ & $30(5.6)$ & $4(3.5)$ & 0.346 \\
\hline Personal reasons & $27(4.2 \%)$ & $23(4.3)$ & $4(3.5)$ & 0.681 \\
\hline
\end{tabular}

CSs could indicate multiple motives for declining participation

${ }^{a}$ Non-participants who returned the postcard, indicating reasons for declining participation

${ }^{\mathrm{b}}$ Non-participants who completed the one-time questionnaire

${ }^{\mathrm{c}} P$ values are the result of chi-square tests between the two groups of non-participants

lived alone. In line with our findings, an earlier study reported that married CSs are at risk for non-participation in supportive programs, compared to unmarried CSs [42]. Another study found that married CSs were more likely to leave the workforce compared to unmarried CSs, although this effect was only found for women [43]. Possibly, married CSs are discouraged to RTW by their spouse for protective reasons. Further, married CSs may not have financial motive for RTW, as their spouse may provide an additional source of income [43]. In these studies, job loss was not taken into account. Potentially, in our study, a lack of financial motive, or a protective attitude from a spouse, prevented married CSs from participation in the supportive RTW program. Conclusively, the factors determining participation of CSs who are married or living together may be more complex compared to factors influencing participation of CSs who are living alone.

CSs with a temporary employment contract prior to job loss were more likely to participate in the RTW program, compared to those with a fixed employment contract prior to job loss. It should be taken into account that, in the Netherlands, CSs with a temporary employment contract may experience job loss earlier in the cancer trajectory, as employers frequently do not renew an expiring temporary contract during sick leave $[10,15]$. Consequently, CSs with a temporary employment contract may have had more urgent financial needs, less RTW support, and more time to consider and prepare for RTW, compared to CSs with a fixed employment contract [10]. This may make CSs with a temporary employment contract more inclined to participate.

A clear intention to RTW was associated with a higher chance of participation in the supportive RTW program. Another recent study indicated that intention to RTW is a strong predictor for actual RTW [9], although not specifically for CSs with job loss. Further, CSs with higher scores on the contemplation scale and the prepared for action-self-evaluative scale of the Readiness to RTW instrument were more likely to participate in the RTW program. As the scales reflect contemplation of RTW and preparation for RTW [30], we hypothesize that, for CSs with job loss with higher scores on these scales, the invitation to participate in the RTW program arrived at a suitable moment.

Interestingly, there was a discrepancy between the multivariable model, which included factors from the sociodemographic and work-related clusters, and the self-reported motives for declining participation, which were more healthrelated. Possibly, there are undetected differences with regard to health status between the non-participants (one-time questionnaire) and the non-participants who only returned the postcard. In this perspective, the multivariable model may represent CSs with job loss who have a relatively good health status.

\section{Strengths and limitations}

The strengths of this study are that data were used from CSs who were recruited on a national level and that a clustered hierarchical analysis approach was applied. The limitations of this study should be recognized as well. First, there is a risk of selection bias in our sample, which might affect generalizability, particularly with regard to CSs experiencing a worse health condition. That is, participants in the RTW program were screened on health-related criteria to determine eligibility for the RCT, while no screening was applied to non-participants, as there was little to no contact with those survivors. If the one-time questionnaire had also been completed by CSs who did not meet the inclusion criteria, this would have improved the generalizability of our results. Further, CSs who do not master the Dutch language may be underrepresented in this study, due to the exclusion criteria of the RCT. Finally, the results of this study should be interpreted in the context of the Dutch 
social security system. Translating our results to other social security systems should be done cautiously.

\section{Implications for future research and practice}

Researchers and practitioners offering RTW support to CSs with job loss should take the presence of (financial) support from a spouse into account, as this may play an important role in the decision of CSs to receive RTW support $[42,43]$. Further, in CSs who had a temporary employment contract, the need for RTW support should be monitored from the start of sick leave, in order to adequately intervene [44]. Practitioners should also inquire about the intention and perceived readiness to RTW [5]. This may facilitate the planning and execution of RTW, e.g., determining the time to RTW or gradual buildup of the workload [10]. Researchers recruiting CSs with job loss for supportive RTW programs should be aware of the role of physical and mental health problems as barriers for participation [17].

\section{Conclusion}

Marital status, type of employment contract, and motivational factors may influence CSs' participation in a supportive RTW program. Considering these factors may aid the identification of CSs who do not need RTW support and those who are in need of RTW support the most. Practitioners and researchers should take CSs' socio-demographic, health-related, and work-related characteristics into account, when offering RTW support. We recommend that future studies in CSs, or other patients with long-term or chronic conditions, collect data regarding (non-)participation. This information can be used to optimize recruitment strategies for supportive RTW programs, in order to provide sick-listed workers with the RTW support that they may need.

Acknowledgments The authors would like to thank K. BonefaasGroenewoud, A.P.J. Scholten, and M. Geldof for their assistance in collecting and processing the data for this study. This study was supported by a grant from the Dutch SSA.

\section{Compliance with ethical standards}

Informed consent Informed consent was obtained from all CSs completed the baseline questionnaire or the one-time questionnaire, as an informed consent form was attached to both questionnaires. For CSs who were included in the non-response analyses, data regarding age, gender, and cancer diagnosis were obtained through the SSA registries. For the use of these anonymous data, informed consent was not obtained. This study was approved by the Medical Ethics Committee of the VU University Medical Center, Amsterdam, The Netherlands.

Open Access This article is distributed under the terms of the Creative Commons Attribution-NonCommercial 4.0 International License (http:// creativecommons.org/licenses/by-nc/4.0/), which permits any noncommercial use, distribution, and reproduction in any medium, provided you give appropriate credit to the original author(s) and the source, provide a link to the Creative Commons license, and indicate if changes were made.

\section{References}

1. Ferlay J, Steliarova-Foucher E, Lortet-Tieulent J, Rosso S, Coebergh JWW, Comber H, Forman D, Bray F (2013) Cancer incidence and mortality patterns in Europe: estimates for 40 countries in 2012. Eur J Cancer 49:1374-1403

2. Dutch Cancer Registry administered by Comprehensive Cancer Centre the Netherlands (Integraal Kankercentrum Nederland) (2015) Cancer Incidence in the Netherlands. Accessed 05-12-2015.

3. Kennedy F, Haslam C, Munir F, Pryce J (2007) Returning to work following cancer: a qualitative exploratory study into the experience of returning to work following cancer. Eur J Cancer Care (Engl) 16:17-25

4. Peteet JR (2000) Cancer and the meaning of work. Gen Hosp Psychiatry 22:200-205

5. Mehnert A (2011) Employment and work-related issues in cancer survivors. Crit Rev Oncol Hematol 77:109-130

6. Harrington CB, Hansen JA, Moskowitz M, Todd BL, Feuerstein M (2010) It's not over when it's over: long-term symptoms in cancer survivors - a systematic review. Int J Psychiatry Med 40:163-181

7. Munir F, Yarker J, McDermott H (2009) Employment and the common cancers: correlates of work ability during or following cancer treatment. Occup Med (Lond) 59:381-389

8. Duijts SFA, van Egmond MP, Spelten E, van Muijen P, Anema JR, van der Beek AJ (2014) Physical and psychosocial problems in cancer survivors beyond return to work: a systematic review. Psychooncology 23:481-492

9. Mehnert A, Koch U (2013) Predictors of employment among cancer survivors after medical rehabilitation - a prospective study. Scand J Work Environ Health 39:76-87

10. van Egmond M, Duijts S, Loyen A, Vermeulen S, van der Beek A, Anema J (2015) Barriers and facilitators for return to work in cancer survivors with job loss experience: a focus group study. Eur J Cancer Care (Engl). doi:10.1111/ecc.12420

11. Uitvoeringsinstituut Werknemersverzekeringen [Dutch Institute for Employee Benefit Schemes] (2014) Quantitative reports of statistics 2013/UWV Kwantitatieve Informatie 2013; pp 10-11.

12. Statistics Netherlands, Centraal Bureau voor de Statistiek (2014) Statistics Netherlands database. Accessed 01-11-2015.

13. Hoppers F (2012) Increase In state pension age from 1 January 2013. Dirkzwager advocaten \& notarissen N.V, Arnhem, The Netherlands

14. Hogelund J (2002) Reintegration: public or private responsibility? Consequences of Dutch and Danish policies toward work-disabled persons. Int J Health Serv 32:467-487

15. Dutch Cancer Patient Movement, Leven met Kanker Beweging (2013) Eenvandaag: Working with cancer. http://www. eenvandaag.nl/uploads/doc/Rapportage $\% 20$ werknemers $\% 20$ met \%20kanker.pdf

16. van Egmond MP, Duijts SF, Vermeulen SJ, van der Beek AJ, Anema JR (2015) Return to work in sick-listed cancer survivors with job loss: design of a randomised controlled trial. BMC Cancer 15:63

17. van Waart H, van Harten W, Buffart L, Sonke G, Stuiver M, Aaronson N (2015) Why do patients choose (not) to participate in 
an exercise trial during adjuvant chemotherapy for breast cancer? Psychooncology. doi:10.1002/pon.3936

18. Tamminga SJ, Verbeek JHAM, Bos MMEM, Fons G, Kitzen JJEM, Plaisier PW, Frings-Dresen MHW, de Boer AGEM (2013) Effectiveness of a hospital-based work support intervention for female cancer patients - a multi-centre randomised controlled trial. PLoS one 8:e63271

19. Thijs KM, de Boer AGEM, Vreugdenhil G, van de Wouw AJ, Houterman S, Schep G (2012) Rehabilitation using high-intensity physical training and long-term return-to-work in cancer survivors. J Occup Rehabil 22:220-229

20. Mills EJ, Seely D, Rachlis B, Griffith L, Wu P, Wilson K, Ellis P, Wright JR (2006) Barriers to participation in clinical trials of cancer: a meta-analysis and systematic review of patient-reported factors. Lancet Oncol 7:141-148

21. Ellis PM, Butow PN, Tattersall MH, Dunn SM, Houssami N (2001) Randomized clinical trials in oncology: understanding and attitudes predict willingness to participate. J Clin Oncol 19:3554-3561

22. Radloff LS (1977) The CES-D scale. Appl Psychol Meas 1:385401

23. Schroevers MJ, Sanderman R, van Sonderen E, Ranchor AV (2000) The evaluation of the Center for Epidemiologic Studies Depression (CES-D) scale: depressed and positive affect in cancer patients and healthy reference subjects. Qual Life Res 9:1015-1029

24. Bouma J, Ranchor A, Sanderman R, E van Sonderen (2012) Het meten van symptomen vandepressie met de CES-D: een handleiding. Tweede Herziene druk; Groningen, UMCG/ Rijksuniversiteit Groningen, Research Institute SHARE.

25. Webster K, Cella D, Yost K (2003) The Functional Assessment of Chronic Illness Therapy (FACIT) Measurement System: properties, applications, and interpretation. Health Qual Life Outcomes 1:79

26. Scheurs PJG, van de Willige G, Brosschot JF, Tellegen B, Graus GMH (1993) De Utrechtse Copinglijst: UCL. ed 2, Swets en Zeitlinger b.v. Lisse

27. Hjermstad MJ, Fossa SD, Bjordal K, Kaasa S (1995) Test/retest study of the European Organization for Research and Treatment of Cancer Core Quality-of-Life Questionnaire. J Clin Oncol 13: $1249-1254$

28. Ilmarinen J, Tuomi K: Work ability index for aging workers (1993) Aging and Work 42-151.

29. van der Zee CH, Priesterbach AR, van der Dussen L, Kap A, Schepers VPM, Visser-Meily JMA, Post MWM (2010) Reproducibility of three self-report participation measures: the ICF Measure of Participation and Activities Screener, the Participation Scale, and the Utrecht Scale for Evaluation of Rehabilitation-Participation. J Rehabil Med 42:752-757

30. Franche RL, Corbiere M, Lee H, Breslin FC, Hepburn CG (2007) The readiness for return-To-work (RRTW) scale: development and validation of a self-report staging scale in lost-time claimants with musculoskeletal disorders. J Occup Rehabil 17:450-472
31. Prochaska JO, DiClemente CC (1983) Stages and processes of selfchange of smoking: toward an integrative model of change. J Consult Clin Psychol 51:390-395

32. van Oostrom SH, Anema JR, Terluin B, de Vet HCW, Knol DL, van Mechelen W (2008) Cost-effectiveness of a workplace intervention for sick-listed employees with common mental disorders: design of a randomized controlled trial. BMC Public Health 8:12

33. Grewal R, Cote JA, Baumgartner H (2004) Multicollinearity and Measurement Error in Structural Equation Models. Implications for theory testing. Mark Sci 23:519-529

34. SPSS Inc (2009) Chicago. Illinois, USA

35. Azarkish F, Mirzaii Najmabadi K, Latifnejad Roudsari R, Homaei Shandiz F (2015) Factors related to return to work in women after breast cancer in Iran. Iran Red Crescent Med J 17:e19978

36. Noeres D, Park-Simon TW, Grabow J, Sperlich S, KochGiesselmann H, Jaunzeme J, Geyer S (2013) Return to work after treatment for primary breast cancer over a 6-year period: results from a prospective study comparing patients with the general population. Support Care Cancer 21:1901-1909

37. van Muijen P, Weevers NLEC, Snels IAK, Duijts SFA, Bruinvels DJ, Schellart AJM, van der Beek AJ (2013) Predictors of return to work and employment in cancer survivors: a systematic review. Eur J Cancer Care (Engl) 22:144-160

38. Statistics Netherlands, Centraal Bureau voor de Statistiek (2014) Socio-economic trends 2014: Judging older and younger workers; pp 1-10.

39. Rijken M, Spreeuwenberg P, Schippers J, Groenewegen PP (2013) The importance of illness duration, age at diagnosis and the year of diagnosis for labour participation chances of people with chronic illness: results of a nationwide panel-study in The Netherlands. BMC Public Health 13:803

40. Courneya KS, Segal RJ, Mackey JR, Gelmon K, Reid RD, Friedenreich CM, Ladha AB, Proulx C, Vallance JKH, Lane K, Yasui Y, McKenzie DC (2007) Effects of aerobic and resistance exercise in breast cancer patients receiving adjuvant chemotherapy: a multicenter randomized controlled trial. J Clin Oncol 25:43964404

41. Duijts SFA, Oldenburg HSA, van Beurden M, Aaronson NK (2009) Cognitive behavioral therapy and physical exercise for climacteric symptoms in breast cancer patients experiencing treatment-induced menopause: design of a multicenter trial. BMC Womens Health 9:15

42. Gruber U, Fegg M, Buchmann M, Kolb HJ, Hiddemann W (2003) The long-term psychosocial effects of haematopoetic stem cell transplantation. Eur J Cancer Care (Engl) 12:249-256

43. Earle CC, Chretien Y, Morris C, Ayanian JZ, Keating NL, Polgreen LA, Wallace R, Ganz PA, Weeks JC (2010) Employment among survivors of lung cancer and colorectal cancer. J Clin Oncol 28: 1700-1705

44. Vermeulen SJ, Tamminga SJ, Schellart AJ, Ybema JF, Anema JR (2009) Return-to-work of sick-listed workers without an employment contract-what works? BMC Public Health 9:232 